\title{
Discovery of Comorbid Psychiatric Conditions among Youth Detainees in Juvenile Justice System using Clinical Data
} \author{
Dhinakaran Rajendran $^{1}$ Laine M. Young-Walker ${ }^{6}$ \\ ${ }^{1}$ Department of Health Management and Informatics, University of \\ Missouri, Columbia, Missouri, United States \\ 2 Institute of Statistical Research and Training, University of Dhaka, \\ Dhaka, Bangladesh \\ ${ }^{3}$ Center for Biomedical Informatics, School of Medicine, University of \\ Missouri, Columbia, Missouri, United States \\ ${ }^{4}$ Institute for Data Science and Informatics, University of Missouri, \\ Columbia, Missouri, United States \\ ${ }^{5}$ Department of Electrical and Computer Science, University of \\ Missouri, Columbia, Missouri, United States \\ ${ }^{6}$ Department of Psychiatry, School of Medicine, University of \\ Missouri, Columbia, Missouri, United States
}

Humayera Islam,2,3 Abu S. M. Mosa 1,3,4,5 Hirsch K. Srivastava ${ }^{6}$ Vasanthi Mandhadi ${ }^{3}$

Address for correspondence Laine M. Young-Walker, MD, Department of Psychiatry, School of Medicine, University of Missouri, 1 Hospital Dr, Columbia, MO 65201, United States (e-mail: YoungWalkerL@health.missouri.edu).

ACI Open 2020;4:e136-e148.

\section{Abstract}

Keywords

- frequent pattern mining

- association rule mining

- comorbid psychiatric disorders

- juvenile justice system

- child and adolescent psychiatry
Objective The main aim was to analyze the prevalence and patterns of comorbidity in 11 identified broad categories of psychiatric conditions and 48 specific psychiatric conditions among 613 youth from the Missouri Division of Youth Services (DYS) residential sites using advanced data mining techniques on clinical assessment data. Methods This study was based on youth detainee population at DYS residential placements receiving psychiatric care through the telemedicine network established between DYS and University of Missouri Department of Psychiatry. Association Rule Mining (ARM) algorithm was used to determine the associations and the co-occurrence pattern among the comorbid psychiatric conditions.

Results About $88 \%$ of the DYS youth are diagnosed with two or more psychiatric disorders. From the ARM analysis, the most commonly co-occurred disorders are obtained as substance-related or -addicted disorders (SUD) and disruptive, impulsecontrol, and conduct disorders (CD) $(n[\%]=258$ [42.1\%], followed by SUD, CD, and depressive disorder (DD) (145 [23.7\%]), SUD, CD, and neurodevelopmental disorder (NDD) (133 [21.7\%]), and DD, CD and NDD (120 [19.6\%]).

Discussion The study found high prevalence of comorbidity among the youth patients of the Missouri DYS facilities receiving care through the University of Missouri telemedicine network. The ideal scenario for assessment of any of these disorders in a patient should include substantial consideration in delineating the symptoms and history before eliminating any of them.

Conclusion The comorbid patterns obtained can help in determining treatment regimens for DYS youth that can be effective in reducing recidivism and delinquency. received

February 12, 2020

accepted after revision

August 27, 2020
DOI https://doi.org/

10.1055/s-0040-1718542.

ISSN 2566-9346. (c) 2020 Georg Thieme Verlag KG

Stuttgart - New York
License terms

(ब)(1) 


\section{Background and Significance}

Many youths under 18 years of age in the United States are incarcerated in the juvenile justice system (JJS) residential facilities. According to the census data of 2016, approximately 46,000 youth juvenile offenders were housed in 1,772 residential placements. ${ }^{1}$ Mental health disorders are highly prevalent among these incarcerated youth, and the prevalence has been consistently higher than those within general population. ${ }^{2}$ In previous studies on juveniles, estimates reveal that approximately 50 to $75 \%$ of youth encountering JJS are diagnosed with at least one diagnosable mental health disorder. ${ }^{3-5}$ Numerous comprehensive studies have indicated that mental health disorders like, depressive disorders (DDs) (major depression, persistent depression, and manic episodes), schizophrenia spectrum disorders (SSD) (psychotic disorders), anxiety disorders (AD) (panic, separation anxiety, and generalized anxiety), obsessive-compulsive related disorder, trauma and stressor related disorders (posttraumatic stress disorder), disruptive behavior disorders (conduct and oppositional defiant disorder), and neurodevelopment disorders (NDD) (attention-deficit hyperactivity disorder [ADHD]), and substance use disorders are commonly found among these incarcerated youth. ${ }^{6-8}$ There is growing evidence that commonly found mental disorders are associated with increase in risks for youth engaging in aggressive behaviors. ${ }^{8,9}$ Thus, addressing the mental health conditions of the incarcerated youth is important in considering treatment response, and lack of such treatment in the residential facilities can lead in worsening effect on offending behavior and delinquency.

The coexistence of more than one mental health disorders in a patient, regardless of causality or chronology is called comorbidity. Comorbidity is common among adolescents with mental health disorders, and nearly two-thirds of the juvenile youth meet the criteria for two or more diagnosable disorders. ${ }^{6,7,10-12}$ Additionally, there is evidence of association of co-presence of conduct disorder and attention-deficit/hyperactivity disorder among adolescence with chronic offending behavior. ${ }^{8,13,14}$ Comorbidity can often lead to increased complexity of treatment as compared with single disorder. This emphasizes the need for different levels of mental health care with varying effective treatment options for the incarcerated youth addressing the varied co-occurrence pattern among them. Knowledge on comorbidity as evidenced from reliable epidemiologic and clinical data can thus play important role in developing effective individualized treatment for delinquent youth. ${ }^{11,15-18}$

The studies that have examined the prevalence of mental health disorders among the juvenile offenders used data obtained through survey studies to identify the relevant cooccurrence pattern for two diagnoses reporting through prevalence and odds ratios (OR). ${ }^{7,8,12,19,20}$ However, the co-occurrence pattern among three or more psychiatric conditions has not been explored on delinquent youth population in any available literature. In this paper, we have focused on identifying the comorbid patterns of mental disorders using data mining techniques on clinical assessment data from incarcerated youth from state of Missouri.
Association rule mining (ARM) have been proven to be useful for mining clinical data for co-occurrence analysis. For example, ARM was applied for identifying co-occurrence patterns in prescription drugs, and disease comorbidity patterns of ADHD, schizophrenia, hyperprolactinemia and diabetes mellitus type 2 , and borderline personality disorder using insurance claims and clinical datasets. ${ }^{21-28}$ Applying data mining algorithms to explore the co-occurrence of psychiatric disorders is a novel approach for the incarcerated population, which led to the main objective of this paper.

\section{Study Objective}

The main objective of this study was to discover the comorbid psychiatric conditions among the youth detainees within the state of Missouri serving under the JJS. In this study, ARM was used to find the prevalent combination of psychiatric disorders, and to identify the co-occurrence patterns among the comorbid disorders.

\section{Methods}

\section{Population Selection and Data Source}

The analysis of this study was done using clinical data on 613 patients from age 11 to 17 years from the residential placements across Missouri serving under the Division of Youth Services (DYS) within the period 2013 to 2017. The youth patients in the Missouri DYS residential centers received psychiatric care by the board-certified child and adolescent psychiatry (CAP) specialists through a telemedicine network established with University of Missouri Department of Psychiatry (MUPC). The delinquent youth patients received complete psychiatric assessment in their first visit by the MUPC CAP specialists. The clinical notes of the patients were collected from the electronic health record (EHR), and mined to extract the psychiatric assessments of each patient during their visits using a semiautomated process. -Fig. 1 illustrates the process applied to extract the assessments for a patient $X$. The notes were first parsed into unique segments, each part was then coded manually to identify the disorders. The psychiatric disorders were mapped to the Diagnostic and Statistical Manual (DSM-5) of Mental Disorders classes. ${ }^{29}$ The team for data collection included a graduate student and a professor of informatics, and training was provided to the graduate student prior to the process. One team member executed the mapping of unique segments to specific disorders, and mapping of specific disorders to DSM- 5 classes, while another team member overviewed the mappings for double-checking. This led to the presence of 11 distinct psychiatric disorder classes such as, AD, bipolar and related disorders (BD), DD, disruptive, impulse-control and conduct disorders (CD), neurocognitive disorders, NDD, obsessivecompulsive and related disorders, schizophrenia spectrum disorders (SSD), sleep-wake disorders, substance-related or -addicted disorders (SUD) and trauma- and stressor-related disorders (TSD). - Table 1 shows the frequency distribution of the specific disorders under the broad DSM- 5 classes for psychiatric disorders. 


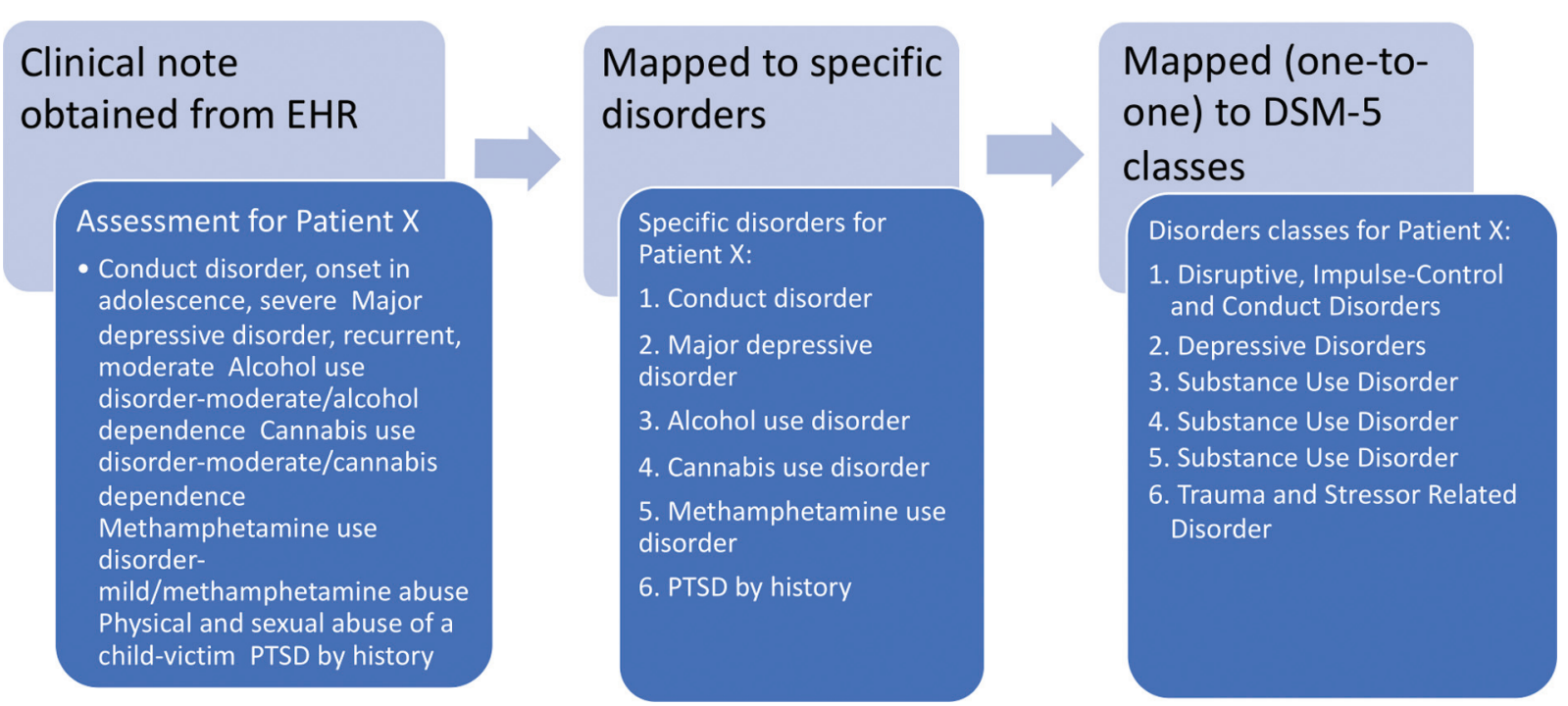

Fig. 1 This figure illustrates the process applied to extract the assessments for a patient $X$. The notes were first parsed into unique segments, each part was then coded manually to identify the disorders. The psychiatric disorders were mapped to the diagnostic and statistical manual-5 of mental disorders classes.

\section{Measure Comorbidity and Comparison by Demographics}

The comorbidity for each DYS youth patient was computed by summing up the number of specific disorders diagnosed for each patient. The frequency distribution of the total diagnosed disorders was compared by the demographic variables like gender and race. The comorbidity was further categorized into two groups: exactly one disorder and two or more disorders, and the frequency distribution for this is also compared by gender and races. The comorbidity among the most common DSM- 5 categories SUD, NDD, CD, and DD with other DSM-5 categories were examined through prevalence ratios and OR. Additionally, prevalence ratios were compared with understand the presence of common specific disorders among the youth patients belonging to the four broad DSM-5 categories.

Descriptive statistics were calculated to examine demographics (race and gender). Statistical tests like Z-test for proportion were performed to compare the proportions between the two groups of comorbidities across demographics. The $p$-values less than 0.05 were set to evaluate statistical significance for OR and Z-tests for proportions. All tests were two-tailed.

\section{Data Mining Approach}

The main aspect of data analyses in this paper is based on the application of the data mining technique known as ARM. The concepts of ARM were first introduced for mining transaction databases to find the most frequent items and to generate significant associations between them. ${ }^{30}$ The clinical assessment data were converted into two types: one using the specific disorders, and the other using the DSM-5 broad classes, merged from the specific disorders. ARM algorithms were applied on each of the datasets. For the purpose of mining, each patient data was considered as a "transaction" in each of the database, and each disorder was considered as an "item." - Fig. 2 shows a sample of the table
(DSM- 5 broad classes) used to perform the analysis. For each patient, there was a list of 0 and 1 , where 0 indicates the absence of the disorder and 1 indicates the presence.

To perform analysis on the psychiatric assessment datasets R (version 3.5.1, R Core Team) ${ }^{31}$ was used, and the library "arules ${ }^{32}$ " was applied to examine the datasets to identify combinations of disorders and their patterns of comorbidity. Computations were performed on a Mac Book Pro running MacOS Catalina version 10.15.2 with 16GB of RAM.

This study utilized the apriori ${ }^{33}$ algorithm, which is the best-known ARM algorithm, to determine rules of the comorbidities among the mental disorders. ARM considers all combinations of psychiatric disorders to identify the combinations of disorders that occur together more often than would expect by chance only. For example, 11 identified DSM-5 categories for psychiatric disorders would result into a total of $2^{11}$ possible combinations of disorders that need to be considered. In apriori setting, the association rules between $A$ and $B$ are expressed as $A \rightarrow B$, where $A$ and $B$ are both disorders, and can be defined as follows: "if disorder $A$ exists, disorder B coexists."

The rules are evaluated according to the values of measures like "support" and "confidence." The support indicates the number of patients with disorder $A$ and $B$ among all patients. The confidence of a rule $A \rightarrow B$ shows the percentage of patients with disorder $B$ among patients with disorder $A$. This measure is comparable to conditional probability of $B$ given $A$ : $P(B \mid A)=\frac{P(A \cap B)}{P(A)}$, which means what is the probability of occurrence of $B$ given that $A$ is known to have occurred. Thus, to capture the interpretation of "confidence" measure as chances of one to be present conditional upon another, we would rename it as "conditional prevalence." The value of confidence will change with change in the denominator, and thus, the rules $A \rightarrow B$ and $B \rightarrow A$ may or may not imply the same. To limit the number of item sets consisting of combinations of disorders, a minimum threshold of support (prevalence) and confidence (conditional prevalence) can be provided. 
Table 1 A table showing the frequency distribution of the 11 broad diagnostic and statistical manual-5 categories and the diagnosed specific disorders among the 613 youth patients

\begin{tabular}{|c|c|c|c|c|c|c|c|}
\hline DSM-V class & Disorder & $n$ & $\%$ & DSM-V Class (cont.) & Disorder (cont.) & $\begin{array}{l}n \\
\text { (cont.) }\end{array}$ & $\begin{array}{l}\text { \% } \\
\text { (cont.) }\end{array}$ \\
\hline $\begin{array}{l}A D \cap(\%)=110 \\
(17.9)\end{array}$ & Claustrophobia & 1 & 0.2 & NDD & Reading disorder & 2 & 0.3 \\
\hline$A D$ & $\begin{array}{l}\text { Social anxiety } \\
\text { disorder }\end{array}$ & 11 & 1.8 & NDD & Tic disorder & 1 & 0.2 \\
\hline$A D$ & Anxiety disorder & 103 & 16.8 & NDD & $\begin{array}{l}\text { Tourette's } \\
\text { syndrome }\end{array}$ & 1 & 0.2 \\
\hline $\begin{array}{l}\text { Bipolar and relat- } \\
\text { ed } \\
\text { disorders } n \\
(\%)=82(13.4)\end{array}$ & $\begin{array}{l}\text { Bipolar mood } \\
\text { disorder }\end{array}$ & 82 & 13.4 & $\begin{array}{l}\text { Obsessive-compul- } \\
\text { sive and related dis- } \\
\text { orders } n(\%)=9(1.5)\end{array}$ & $\begin{array}{l}\text { Obsessive-com- } \\
\text { pulsive disorder }\end{array}$ & 9 & 1.5 \\
\hline $\begin{array}{l}\mathrm{DD} n(\%)=333 \\
(54.3)\end{array}$ & Depressive disorder & 67 & 10.9 & SS $n(\%)=13(2.1)$ & Psychosis & 6 & 1.0 \\
\hline DD & $\begin{array}{l}\text { Disruptive mood } \\
\text { disorder }\end{array}$ & 19 & 3.1 & SS & $\begin{array}{l}\text { Schizoaffective } \\
\text { disorder }\end{array}$ & 5 & 0.8 \\
\hline $\mathrm{DD}$ & Dysthymia & 8 & 1.3 & SS & Schizophrenia & 2 & 0.3 \\
\hline DD & $\begin{array}{l}\text { Major depressive } \\
\text { disorder }\end{array}$ & 74 & 12.1 & SWD $n(\%)=38(6.2)$ & Insomnia & 25 & 4.1 \\
\hline $\mathrm{DD}$ & Mood disorder & 190 & 31.0 & SWD & Primary insomnia & 12 & 2.0 \\
\hline $\begin{array}{l}\text { Disruptive, im- } \\
\text { pulse-control, } \\
\text { and CD n } \\
(\%)=393(64.1)\end{array}$ & Conduct disorder & 288 & 47.0 & SWD & Sleep walking & 1 & 0.2 \\
\hline $\begin{array}{l}\text { Disruptive, im- } \\
\text { pulse-control, } \\
\text { and CD }\end{array}$ & $\begin{array}{l}\text { Impulsive control } \\
\text { disorder }\end{array}$ & 10 & 1.6 & $\begin{array}{l}\text { SUD } n(\%)=358 \\
(58.4)\end{array}$ & $\begin{array}{l}\text { Inhalant use } \\
\text { disorder }\end{array}$ & 6 & 1.0 \\
\hline $\begin{array}{l}\text { Disruptive, im- } \\
\text { pulse-control, } \\
\text { and CD }\end{array}$ & $\begin{array}{l}\text { Intermittent explo- } \\
\text { sive disorder }\end{array}$ & 2 & 0.3 & SUD & $\begin{array}{l}\text { Phencyclidine } \\
\text { use disorder }\end{array}$ & 3 & 0.5 \\
\hline $\begin{array}{l}\text { Disruptive, im- } \\
\text { pulse-control, } \\
\text { and CD }\end{array}$ & $\begin{array}{l}\text { Oppositional defiant } \\
\text { disorder }\end{array}$ & 125 & 20.4 & SUD & $\begin{array}{l}\text { Alcohol use } \\
\text { disorder }\end{array}$ & 167 & 27.2 \\
\hline $\begin{array}{l}\text { Neurocognitive } \\
\text { disorder } n(\%)=1 \\
(0.2)\end{array}$ & Cognitive disorder & 1 & 0.2 & SUD & CUD & 339 & 55.3 \\
\hline $\begin{array}{l}\text { NDD } n \mid(\%)=329 \\
(52.2)\end{array}$ & $\begin{array}{l}\text { Attention-deficit/hy- } \\
\text { peractivity disorder }\end{array}$ & 309 & 50.4 & SUD & $\begin{array}{l}\text { Hallucinogen use } \\
\text { disorder }\end{array}$ & 10 & 1.6 \\
\hline NDD & $\begin{array}{l}\text { Asperger's } \\
\text { syndrome }\end{array}$ & 4 & 0.7 & SUD & $\begin{array}{l}\text { Opioid use } \\
\text { disorder }\end{array}$ & 33 & 5.4 \\
\hline NDD & $\begin{array}{l}\text { Autism spectrum } \\
\text { disorder }\end{array}$ & 1 & 0.2 & SUD & $\begin{array}{l}\text { Sedative-hypnot- } \\
\text { ic and anxiolytic } \\
\text { use disorder }\end{array}$ & 19 & 3.1 \\
\hline NDD & $\begin{array}{l}\text { Borderline intellec- } \\
\text { tual functioning }\end{array}$ & 3 & 0.5 & SUD & $\begin{array}{l}\text { Stimulant use } \\
\text { disorder }\end{array}$ & 36 & 5.9 \\
\hline NDD & Intellectual disability & 3 & 0.5 & SUD & $\begin{array}{l}\text { Tobacco use } \\
\text { disorder }\end{array}$ & 70 & 11.4 \\
\hline NDD & Learning disorder & 6 & 1.0 & $\begin{array}{l}\text { TSD } n(\%)=114 \\
(18.6)\end{array}$ & $\begin{array}{l}\text { Acute stress } \\
\text { disorder }\end{array}$ & 2 & 0.3 \\
\hline NDD & $\begin{array}{l}\text { Mathematics } \\
\text { disorder }\end{array}$ & 1 & 0.2 & TSD & $\begin{array}{l}\text { Adjustment } \\
\text { disorder }\end{array}$ & 18 & 2.9 \\
\hline NDD & Mental retardation & 1 & 0.2 & TSD & $\begin{array}{l}\text { Posttraumatic } \\
\text { stress disorder }\end{array}$ & 95 & 15.5 \\
\hline NDD & $\begin{array}{l}\text { Phonological } \\
\text { disorder }\end{array}$ & 1 & 0.2 & TSD & $\begin{array}{l}\text { Reactive attach- } \\
\text { ment disorder }\end{array}$ & 2 & 0.3 \\
\hline
\end{tabular}

Abbreviations: AD, anxiety disorder; CD, conduct disorder; DD, depressive disorder; DSM-5, diagnostic and statistical manual-5; NDD, neurodevelopment disorder; SUD, substance-related or addicted disorder; SWD, sleep-wake disorder; TSD, trauma- and stressor-related disorder. 


\begin{tabular}{|c|c|c|c|c|c|c|c|c|c|c|c|}
\hline Patient ID & SUD & AD & BD & DD & DCD & NCD & NDD & OCD & SS & SWD & TSD \\
\hline 1 & 1 & 0 & 0 & 1 & 1 & 0 & 0 & 0 & 0 & 0 & 0 \\
\hline 2 & 0 & 0 & 0 & 1 & 1 & 0 & 0 & 0 & 0 & 0 & 0 \\
\hline 3 & 0 & 0 & 0 & 0 & 1 & 0 & 1 & 0 & 0 & 0 & 0 \\
\hline 4 & 0 & 0 & 0 & 1 & 0 & 0 & 1 & 0 & 0 & 0 & 0 \\
\hline 5 & 1 & 0 & 0 & 1 & 1 & 0 & 0 & 0 & 0 & 0 & 1 \\
\hline 6 & 1 & 0 & 0 & 0 & 1 & 0 & 1 & 0 & 0 & 0 & 0 \\
\hline 7 & 0 & 0 & 0 & 1 & 1 & 0 & 1 & 0 & 0 & 0 & 0 \\
\hline 8 & 1 & 1 & 0 & 1 & 1 & 0 & 0 & 0 & 0 & 0 & 0 \\
\hline 9 & 1 & 0 & 1 & 1 & 1 & 0 & 0 & 0 & 0 & 0 & 0 \\
\hline 10 & 1 & 0 & 0 & 1 & 1 & 0 & 0 & 0 & 0 & 0 & 0 \\
\hline
\end{tabular}

Fig. 2 This shows a sample of the table (diagnostic and statistical manual-5 broad classes) used to perform the analysis. For each patient, there exists a list of 0 and 1 , where 0 indicates the absence of the disorder and 1 indicates the presence. AD, anxiety disorder; BD, bipolar and related disorders; DCD, disruptive, impulse-control and conduct disorders; DD, depressive disorder; NCD, neurocognitive disorders; NDD, neurodevelopment disorder; OCD, obsessive-compulsive disorder.

$$
\begin{gathered}
\operatorname{supp}(A \rightarrow B)=\frac{\text { Number of patients with } A \text { and } B}{\text { Total number of patients }} \\
\operatorname{conf}(A \rightarrow B)=\frac{\text { Number of patients with } A \text { and } B}{\text { Number of patients with disorder } A}
\end{gathered}
$$

To measure the "interestingness" of the relationships obtained from ARM, interest measures Chi-squared statistic and odds ratios are computed for each rule. ${ }^{34}$ Significant $p$ values ( $p$-values less than 0.05 ) obtained from the Chisquared statistic indicate stronger evidence that the rule represents a strong relationship. OR of value greater than one indicates the odds of having disorder $B$ among patients having disorder $\mathrm{A}$ are greater than $100 \%$.

\section{Results}

Among the 613 patients, there are 77 (12.6\%) females and $533(86.9 \%)$ males (with three patients with missing gender information), and $292(47.6 \%)$, and 282 (46\%) patients with white and black races, respectively. From the clinical diagnoses of the 613 youth detainees in the DYS facilities, 11 broad DSM- 5 classes of psychiatric disorders is identified with 46 specific disorders under those categories. The total number of specific disorders is computed for each patient, which reflects the co-presence of multiple disorders among the DYS youth. - Fig. 3 shows the frequency distribution of total diagnosed disorders versus gender and race variables. Female youth patients are seen to have greater proportions for multiple disorders as compared with that of male youths. Moreover, white youths are seen to have more significant percentages for higher diagnosed disorder number as compared with black youths. - Table 2 provides a frequency distribution categorizing the total diagnosed disorders into two groups: exactly one disorder and two or more disorders versus gender and race. Evidently, significantly more males and females have two or more specific disorders, and more white youths than black youths have two or more diagnosed disorders in this population. This shows that the youth patients in the DYS facilities are commonly diagnosed with multiple disorders that need to be addressed for treatment simultaneously
From - Table 1 we can see that among the broad DSM-5 categories, disruptive, impulse-control, and CD, have the maximum prevalence with 393 (64.1\%) youth patients, followed by substance-related or addicted disorders (SUD) with $n$ $(\%)=358(58.4)$, DD with $n(\%)=333(54.3)$, and neurodevelopment disorders (NDD) with $n(\%)=329$ (52.2). Among the specific disorders under the DSM-5 categories, cannabis use disorder (CUD) has the maximum prevalence $(n[\%]=339$ [55.3]), followed by ADHD ( $n[\%]=309$ [50.4]), conduct disor$\operatorname{der}(n[\%]=228[47.0])$, and mood disorder $(n[\%]=190[31.0])$.

-Table 3 summarizes the comorbid disorders with the most frequent DSM-5 categories CD, SUD, DD, and NDD. Among the patients diagnosed with $\mathrm{CD}(n=393)$, the most co-occurred disorder is SUD $(n[\%]=258$ [67.4]) with OR of 2.290 ( $p$-value $<0.05$ ). The comorbid disorders co-occurring with patients diagnosed with SUD $(n=358)$ are CD $(n$ $[\%]=258$ [72.1], OR: $2.29[p$-value $<0.05])$ and $\mathrm{AD}(n$ $[\%]=80[22.3]$, OR: 2.156 [ $p$-value $<0.05])$. Among the patients diagnosed with NDD $(n=329)$, CD and SUD occurred for $65.7 \%(n=216)$ and $53.5 \%(n=176)$ of the cases, respectively; however, their OR are not significant ( $p$-values $>0.05$ ). TSD and AD co-occurred with NDD approximately $15 \%$ cases with $\mathrm{OR}$ of less than 1 ( $p$-values $<0.05$ ), respectively. CD and SUD co-occurred with DD $(n=333)$ $66.7 \%(n=222)$ and $58 \%(n=193)$ of the cases, respectively; however, with not significant OR ( $p$-value $>0.05$ ).

- Fig. 4 shows the common specific disorders present under the broad DSM-5 categories CD, DD, NDD, and SUD. ADHD, alcohol use disorder (AUD), CUD, and mood disorder with 52.7, 33.1, 62.3, and 32.6\%, respectively, are found as comorbid disorders with category CD. Youth patients who are diagnosed with SUD, also have specific disorders ADHD (47.8\%), conduct disorder (54.2\%), and mood disorder (30.2\%) as comorbid disorders. CUD (50.8\%), conduct disorder (44.7\%), and mood disorder (33.7\%) have co-occurred with youth patients diagnosed with any NDD. Patients diagnosed with any disorder under DD, also have ADHD (46.2\%), AUD (30.3\%), CUD (56.2\%), and conduct disorder (48.6\%).

- Table 4 provides the association rules obtained from ARM technique applied to the broad categories of the psychiatric 

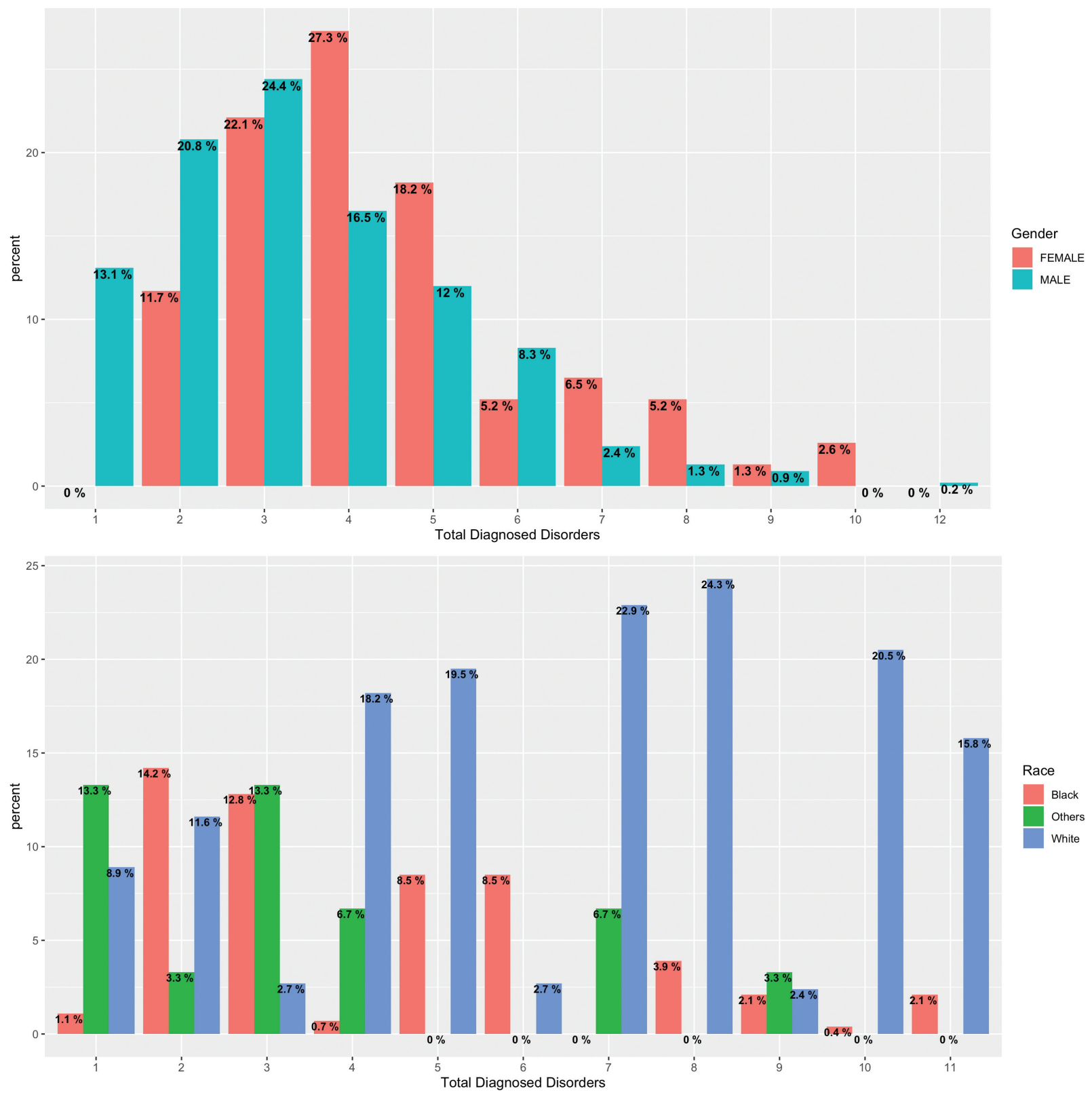

Fig. 3 This shows the frequency distribution of total diagnosed disorders versus gender and race variables.

Table 2 A table showing the frequency distribution categorizing the total diagnosed disorders into two groups: exactly one disorder and two or more disorders versus gender and race

\begin{tabular}{|c|c|c|c|}
\hline Demographics & $\begin{array}{l}\text { Exactly one specific } \\
\text { disorder } n(\%)\end{array}$ & $\begin{array}{l}\text { Two or more specific } \\
\text { disorders } n(\%)\end{array}$ & $\begin{array}{l}p \text {-Value from } \\
\text { proportion test }\end{array}$ \\
\hline \multicolumn{4}{|l|}{ Gender } \\
\hline Male $(n=533)$ & $70(13.1)$ & 463 (86.9) & $0.000^{\mathrm{a}}$ \\
\hline Female $(n=77)$ & $0(0)$ & $77(100)$ & $0.000^{\mathrm{a}}$ \\
\hline \multicolumn{4}{|l|}{ Races } \\
\hline White $(n=292)$ & $26(8.9)$ & $266(91.1)$ & $0.000^{\mathrm{a}}$ \\
\hline Black $(n=282)$ & $34(12.1)$ & $248(87.9)$ & $0.000^{\mathrm{a}}$ \\
\hline Others $(n=30)$ & $8(26.7)$ & $22(73.3)$ & $0.000^{\mathrm{a}}$ \\
\hline
\end{tabular}

a Shows the $p$-values that are significant. 
Table 3 A table showing the comorbid disorders with the most frequent diagnostic and statistical manual-5 categories: conduct, depressive, neurodevelopmental, and substance-related or -addicted disorders

\begin{tabular}{|c|c|c|c|c|}
\hline $\begin{array}{l}\text { Patients with SUD having other } \\
\text { common disorders }(n=358)\end{array}$ & Prevalence (\%) & Odds ratios & $\begin{array}{l}\text { Confidence level } \\
\text { (lower, upper) }\end{array}$ & $p$-Value \\
\hline CD & $258(72.1)$ & 2.290 & $(1.6-3.3)$ & $0^{\mathrm{a}}$ \\
\hline DD & $193(53.9)$ & 0.961 & $(0.7-1.3)$ & 0.869 \\
\hline NDD & $176(49.2)$ & 0.746 & $(0.5-1.0)$ & 0.085 \\
\hline AD & $80(22.3)$ & 2.156 & $(1.3-3.5)$ & $0.001^{\mathrm{a}}$ \\
\hline TSD & $61(17.0)$ & 0.783 & $(0.5-1.2)$ & 0.248 \\
\hline \multicolumn{5}{|c|}{ Patients with NDD having other common disorders $(n=329)$} \\
\hline CD & $216(65.7)$ & 1.360 & $(1.0-1.9)$ & 0.077 \\
\hline SUD & $176(53.5)$ & 0.746 & $(0.5-1.0)$ & 0.085 \\
\hline DD & $162(49.2)$ & 0.732 & $(0.5-1.0)$ & 0.062 \\
\hline TSD & $49(14.9)$ & 0.635 & $(0.4-1.0)$ & $0.03^{\mathrm{a}}$ \\
\hline AD & $47(14.3)$ & 0.629 & $(0.4-1.0)$ & $0.035^{\mathrm{a}}$ \\
\hline \multicolumn{5}{|c|}{ Patients with CD having other common disorders $(n=393)$} \\
\hline SUD & $258(67.4)$ & 2.290 & $(1.6-3.3)$ & $0^{\mathrm{a}}$ \\
\hline $\mathrm{DD}$ & $222(58.0)$ & 1.274 & $(0.9-1.8)$ & 0.152 \\
\hline NDD & $216(56.4)$ & 1.360 & $(1.0-1.9)$ & 0.077 \\
\hline TSD & $74(19.3)$ & 1.044 & $(0.7-1.6)$ & 0.914 \\
\hline$A D$ & $68(17.8)$ & 0.887 & $(0.6-1.4)$ & 0.585 \\
\hline $\mathrm{BD}$ & $47(12.3)$ & 0.718 & $(0.4-1.2)$ & 0.175 \\
\hline \multicolumn{5}{|c|}{ Patients with DD having other common disorders ( $n=333$ ) } \\
\hline CD & $222(66.7)$ & 1.274 & $(0.9-1.8)$ & 0.152 \\
\hline SUD & $193(58.0)$ & 0.961 & $(0.7-1.3)$ & 0.869 \\
\hline NDD & $162(48.6)$ & 0.732 & $(0.5-1.0)$ & 0.062 \\
\hline TSD & $64(19.2)$ & 1.094 & $(0.7-1.7)$ & 0.678 \\
\hline$A D$ & $61(18.3)$ & 1.057 & $(0.6-1.6)$ & 0.833 \\
\hline
\end{tabular}

Abbreviations: $A D$, anxiety disorder; BD, bipolar and related disorder; $C D$, conduct disorder; DD, depressive disorder; NDD, neurodevelopment disorder; SUD, substance-related or addicted disorder; SWD, sleep-wake disorder; TSD, trauma- and stressor-related disorder.

${ }^{a} p$-Values less than 0.05 are considered to be significant.

conditions. The rules are filtered based on the $p$-values from Chi-square test from 52 rules obtained, and only the rules with $p$-values of less than 0.05 are retained in the table (significant rules meaning strong association). The most commonly cooccurred disorders in this youth detainee population are SUD and $\mathrm{CD}(n[\%]=258[42.1])$, followed by SUD, CD and DD $(n$ $[\%]=145$ [23.7]), SUD, CD, and NDD ( $n[\%]=133$ [21.7]), and $\mathrm{DD}, \mathrm{CD}$, and $\operatorname{NDD}(n[\%]=120[19.6])$. There are $72.1 \%$ chances for CD to co-occur with SUD and DD, with OR of 2.095, as shown by the rule $\{S U D, D D\} \rightarrow\{C D\}$. Also, chances for $C D$ to be co-present with \{SUD and NDD $\},\{$ DD and NDD $\},\{$ SUD, DD, and NDD\}, and [DD and TSD \} are 75.6, 74.1, 79.3, and 76.6\%, respectively; all rules with OR of greater than one. The chances for SUD to co-occur with $\{\mathrm{DD}$ and $C D$ \} are $65.3 \%$ with OR of $1.574(\{C D, D D\} \rightarrow\{S U D\})$. Moreover, SUD has $72.7 \%$ chances (OR: 2.158) to co-occur with AD, 73.5\% chances (OR: 2.137) to co-occur with $\{A D$ and $C D\}$ and $73.8 \%$ chances (OR: 2.148) to co-occur with $\{A D$ and $D D\}$.

The association rules obtained from the specific disorders under the broad categories are summarized in -Table 5 with interest measures OR and $p$-values from Chi-square test. The rules with significant Chi-square association ( $p$-value $<0.05$ ) are retained in the table. The most commonly found comorbid specific disorders are CD and CUD $(n[\%]=184[30])$, followed by AUD and CUD ( $n$ $[\%]=154$ [25.1]) and AUD and CD $(n(\%)=102$ [16.6]). CUD has 92.2\% chances to co-occur with AUD (OR: 16.713), 90\% chances with tobacco use disorder (OR: 8.707), $86.1 \%$ chances with stimulant use disorder, $69.9 \%$ chances with anxiety disorder (OR: 2.114 ) and $63.9 \%$ with conduct disorder (OR: 1.940). There are 35 cases (5.7\%) with comorbid disorders-CD, mood disorder, AUD and CUD, and CUD has co-occurred with the other three $100 \%$ of the cases. In cases where AUD is combined with mood disorder and ADHD, the chances of CUD is 97\% (OR: 28.456). Moreover, when AUD is combined with ADHD and conduct disorder, chances of CUD is $93.9 \%$ (OR: 14.182), when combined with anxiety disorder, chances are $91.7 \%$ (OR: 9.742), and when combined with oppositional defiant disorder, chances are 91.4\% (OR: 9.416). 


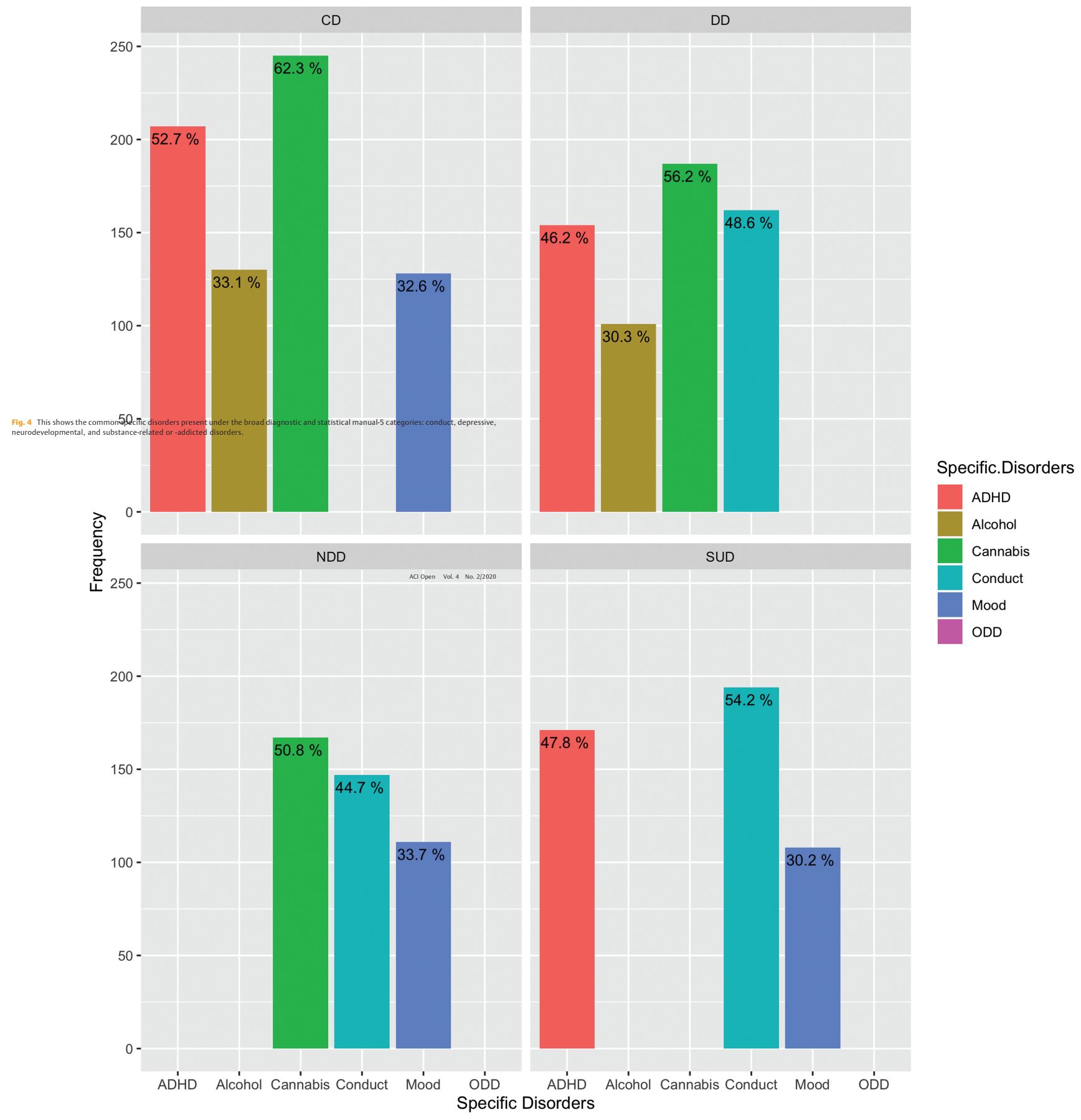

\section{Discussion}

This study has focused on utilizing a data mining technique called ARM to analyze clinical assessment data from the population of youth juvenile detainees in Missouri DYS custody. In ARM, "confidence" represents the probability of the predicted event given the co-occurrence of other event(s) and "support" provides how frequently a set of events co- occur in the database. This study used analogical terms like "conditional prevalence" to determine the chances of diagnosis of one psychiatric disorder conditional upon co-presence of other psychiatric disorder(s), and "prevalence" as a measure of how frequently the comorbid psychiatric disorders co-occur. Interest measures like $\mathrm{OR}$ and $p$-values obtained from Chi-square test of association were used to determine which associations are strong and significant. This 
Table 4 Association rules obtained from applying the association rule on the broad categories of the psychiatric conditions

\begin{tabular}{|l|l|l|l|l|}
\hline Association rules & $\boldsymbol{n}(\%)$ & Conditional prevalence & Odds ratio & $\begin{array}{l}p \text {-Value } \\
\text { Chi-square test }\end{array}$ \\
\hline$\{\mathrm{SUD}\} \rightarrow\{\mathrm{CD}\}$ & $258(42.1)$ & 72.1 & 2.293 & 0.000 \\
\hline$\{\mathrm{CD}\} \rightarrow\{\mathrm{SUD}\}$ & $258(42.1)$ & 65.6 & 2.293 & 0.000 \\
\hline$\{\mathrm{SUD}, \mathrm{DD}\} \rightarrow\{\mathrm{CD}\}$ & $145(23.7)$ & 75.1 & 2.095 & 0.000 \\
\hline$\{\mathrm{DD}, \mathrm{CD}\} \rightarrow\{\mathrm{SUD}\}$ & $145(23.7)$ & 65.3 & 1.574 & 0.009 \\
\hline$\{\mathrm{SUD}, \mathrm{NDD}\} \rightarrow\{\mathrm{CD}\}$ & $133(21.7)$ & 75.6 & 2.106 & 0.000 \\
\hline$\{\mathrm{DD}, \mathrm{NDD}\} \rightarrow\{\mathrm{CD}\}$ & $120(19.6)$ & 74.1 & 1.863 & 0.002 \\
\hline$\{\mathrm{AD}\} \rightarrow\{\mathrm{SUD}\}$ & $80(13.1)$ & 72.7 & 2.158 & 0.001 \\
\hline$\{\mathrm{SUD}, \mathrm{DD}, \mathrm{NDD}\} \rightarrow\{\mathrm{CD}\}$ & $73(11.9)$ & 79.3 & 2.413 & 0.001 \\
\hline$\{\mathrm{AD}, \mathrm{CD}\} \rightarrow\{\mathrm{SUD}\}$ & $50(8.2)$ & 73.5 & 2.137 & 0.007 \\
\hline$\{\mathrm{AD}, \mathrm{DD}\} \rightarrow\{\mathrm{SUD}\}$ & $45(7.3)$ & 73.8 & 2.148 & 0.01 \\
\hline$\{\mathrm{DD}, \mathrm{TSD}\} \rightarrow\{\mathrm{CD}\}$ & $49(8.0)$ & 76.6 & 1.947 & 0.028 \\
\hline$\{\mathrm{CD}, \mathrm{TSD}\} \rightarrow\{\mathrm{DD}\}$ & $49(8.0)$ & 66.2 & 1.76 & 0.029 \\
\hline
\end{tabular}

${ }^{a}$ All p-values are significant.

Abbreviations: $A D$, anxiety disorder; $B D$, bipolar and related disorder; $C D$, conduct disorder; $D D$, depressive disorder; NDD, neurodevelopment disorder; SUD, substance-related or addicted disorder; SWD, sleep-wake disorder; TSD, trauma- and stressor-related disorder.

data mining approach is novel specific to this population as no other literature has been found to identify the comorbidity among more than two psychiatric conditions for the juvenile youth population using advanced data mining algorithms. Moreover, the use of clinical records from EHR in our study rather than interview questionnaires, such as the Diagnostic Interview Schedule for Children (DISC), to identify the psychiatric conditions is believed to provide better reliable insight into the real-world scenario of comorbidity. Survey questionnaires like DISC are not inclusive of many psychiatric conditions, ${ }^{35}$ and thus, it can be claimed that clinical assessments done through regular doctor visits through a standard of care can capture a broader spectrum of disorders compared with any questionnaire-based assessment results.

The prevalence of psychiatric disorders and the comorbidities found in the general youth population of the United States is comparable to that of the Missouri DYS youth detainees. Among the general youth population, CD (74.2\%, OR: 3.4), ADHD (63.6\%, OR: 3.0), DD (52.7\%, OR: 5.6), AD (24.6\%, OR: 4.6), and TSD (50.6, OR: 2.9) are most commonly found to coexist with SUD. ${ }^{36}$ Another study estimated $23.1 \%$ of general youth with SUD to have ADHD and other NDD diagnoses, ${ }^{37}$ which is almost half to the prevalence of ADHD among SUD youth in our study ( $n[\%]=176[49.2])$. One study estimated that 45 to $50 \%$ of youth in general with ADHD are also diagnosed with $\mathrm{CD}$, which is less than what we found in our sample of DYS youth $(n[\%]=216$ [65.7]). However, juvenile facilities often have inadequate treatment facilities for the youth detainees with no access to CAP specialists, ${ }^{20,38-40}$ which implies limited efficacy in designing treatment for co-occurring psychiatric conditions for this population. Hence, we can infer that though comorbidity is a significant problem among the youth jail detainees com- pared with that of the general youth population across the country, the existing lack of access to proper care for the youth detainees can lead to increase future recidivism and delinquency.

The study on incarcerated adults by Abram et al (1991) found that the vast majority of detainees met the criteria for alcohol disorders, drug disorders, or antisocial personality disorder. ${ }^{10}$ In our study, substance-related or addicted disorders (SUD) account for $58.4 \%$ of the cases with $94.5 \%$ CUD diagnosis. However, youth detainees from our study are diagnosed with conduct related disorders and DDs like ADHD in more significant percentage than adult detainees. Our results from this study are more aligned compared with the existing literature on adolescents in juvenile detention. A meta-regression analysis of 25 studies of adolescents in juvenile detention and correctional facilities found that $C D$ was the most common of the studied disorders with similar prevalence of slightly over $50 \%$ across sexes. ${ }^{2}$ Interestingly, the meta-analysis study showed that among the 13 surveys of 14,639 adolescents, approximately $21.6 \%$ were diagnosed with ADHD. Washburn et al study ${ }^{7}$ on 1,715 arrested and detained youths over age 13 estimated diagnoses of $C D$ to be $38 \%$ and SUD to be 51 to $55 \%$. In the Teplin et al study ${ }^{12}$ of 1,829 detained youths aged 10 to 18 , SUD was diagnosed between 46 and $50 \%$, and CD was diagnosed between 37 and $40 \%$. The DYS youth showed a greater prevalence of CD (64.1\%) and SUD (58.4\%), while approximately twice for ADHD (50.4\%) as compared with these studies on youth detainees.

Abram et $a 1^{17}$ assessed comorbidity of psychiatric diagnoses of 1,829 youth detainee participants utilizing the DISC Version 2.3 for disorder assessment and DSM-III-R for categorization. For example, they have merged disorders like ADHD, ODD, and CD into one category and named it ADHD 
Table 5 The association rules obtained from the specific disorders under the broad categories are summarized with interest measures: odds ratios and $p$-values from Chi-square test

\begin{tabular}{|c|c|c|c|c|c|}
\hline Association rules & $n$ & $\%$ & Conditional prevalence & $p$-Value Chi-square test & Odds ratio \\
\hline$\{C D\} \rightarrow\{C U D\}$ & 184 & 30.0 & 63.9 & 0.000 & 1.94 \\
\hline$\{C U D\} \rightarrow\{C D\}$ & 184 & 30.0 & 54.3 & 0.000 & 1.94 \\
\hline$\{$ AUD $\} \rightarrow\{C U D\}$ & 154 & 25.1 & 92.2 & 0.000 & 16.713 \\
\hline$\{A \cup D\} \rightarrow\{C D\}$ & 102 & 16.6 & 61.1 & 0.000 & 2.194 \\
\hline$\{C D, A \cup D\} \rightarrow\{C \cup D\}$ & 96 & 15.7 & 94.1 & 0.000 & 17.646 \\
\hline$\{\mathrm{AUD}, \mathrm{CUD}\} \rightarrow\{C D\}$ & 96 & 15.7 & 62.3 & 0.000 & 2.302 \\
\hline$\{\mathrm{CD}, \mathrm{CUD}\} \rightarrow\{\mathrm{AUD}\}$ & 96 & 15.7 & 52.2 & 0.000 & 5.501 \\
\hline$\{$ ADHD, CUD $\} \rightarrow\{C D\}$ & 88 & 14.4 & 54.3 & 0.029 & 1.492 \\
\hline$\{\mathrm{ADHD}, \mathrm{CD}\} \rightarrow\{\mathrm{CUD}\}$ & 88 & 14.4 & 62.9 & 0.041 & 1.497 \\
\hline$\{\mathrm{ODD}\} \rightarrow\{\mathrm{ADHD}\}$ & 76 & 12.4 & 60.8 & 0.009 & 1.697 \\
\hline$\{\mathrm{AD}\} \rightarrow\{C \cup D\}$ & 72 & 11.7 & 69.9 & 0.001 & 2.114 \\
\hline$\{$ ADHD, AUD $\} \rightarrow\{C U D\}$ & 68 & 11.1 & 90.7 & 0.000 & 9.571 \\
\hline$\{$ TUD $\} \rightarrow\{C U D\}$ & 63 & 10.3 & 90.0 & 0.000 & 8.707 \\
\hline$\{\mathrm{MD}, \mathrm{CUD}\} \rightarrow\{\mathrm{ADHD}\}$ & 62 & 10.1 & 59.6 & 0.039 & 1.566 \\
\hline$\{\mathrm{MD}, \mathrm{AUD}\} \rightarrow\{\mathrm{CUD}\}$ & 57 & 9.3 & 96.6 & 0.000 & 27.489 \\
\hline$\{\mathrm{MD}, \mathrm{CUD}\} \rightarrow\{\mathrm{AUD}\}$ & 57 & 9.3 & 54.8 & 0.000 & 4.399 \\
\hline$\{\mathrm{CD}, \mathrm{MD}\} \rightarrow\{\mathrm{ADHD}\}$ & 55 & 9.0 & 62.5 & 0.014 & 1.778 \\
\hline$\{\mathrm{TUD}\} \rightarrow\{\mathrm{AUD}\}$ & 50 & 8.2 & 71.4 & 0.000 & 9.103 \\
\hline$\{\mathrm{MDD}\} \rightarrow\{C D\}$ & 49 & 8.0 & 66.2 & 0.000 & 2.46 \\
\hline$\{$ ADHD, AUD $\} \rightarrow\{C D\}$ & 49 & 8.0 & 65.3 & 0.001 & 2.358 \\
\hline$\{\mathrm{ADHD}, \mathrm{CD}, \mathrm{AUD}\} \rightarrow\{\mathrm{CUD}\}$ & 46 & 7.5 & 93.9 & 0.000 & 14.182 \\
\hline$\{A D H D, A U D, C U D\} \rightarrow\{C D\}$ & 46 & 7.5 & 67.6 & 0.000 & 2.618 \\
\hline$\{\mathrm{ADHD}, \mathrm{CD}, \mathrm{CUD}\} \rightarrow\{\mathrm{AUD}\}$ & 46 & 7.5 & 52.3 & 0.000 & 3.657 \\
\hline$\{$ AUD, TUD $\} \rightarrow\{C U D\}$ & 44 & 7.2 & 88.0 & 0.000 & 6.662 \\
\hline$\{$ CUD, TUD $\} \rightarrow\{$ AUD $\}$ & 44 & 7.2 & 69.8 & 0.000 & 8.039 \\
\hline$\{$ ADHD, TUD $\} \rightarrow\{C U D\}$ & 36 & 5.9 & 90.0 & 0.000 & 8.02 \\
\hline$\{C D, M D, A \cup D\} \rightarrow\{C U D\}$ & 35 & 5.7 & 100.0 & 0.000 & NA \\
\hline$\{\mathrm{CD}, \mathrm{MD}, \mathrm{CUD}\} \rightarrow\{\mathrm{AUD}\}$ & 35 & 5.7 & 63.6 & 0.000 & 5.648 \\
\hline$\{\mathrm{MD}, \mathrm{AUD}, \mathrm{CUD}\} \rightarrow\{C D\}$ & 35 & 5.7 & 61.4 & 0.022 & 1.905 \\
\hline$\{\mathrm{MD}, \mathrm{AUD}\} \rightarrow\{\mathrm{CD}\}$ & 35 & 5.7 & 59.3 & 0.046 & 1.735 \\
\hline$\{\mathrm{AD}, \mathrm{AUD}\} \rightarrow\{\mathrm{CUD}\}$ & 33 & 5.4 & 91.7 & 0.000 & 9.742 \\
\hline$\{\mathrm{MDD}, \mathrm{CUD}\} \rightarrow\{\mathrm{CD}\}$ & 33 & 5.4 & 70.2 & 0.001 & 2.875 \\
\hline$\{\mathrm{ODD}, \mathrm{AUD}\} \rightarrow\{\mathrm{CUD}\}$ & 32 & 5.2 & 91.4 & 0.000 & 9.416 \\
\hline$\{$ ADHD, MD, AUD $\} \rightarrow\{C U D\}$ & 32 & 5.2 & 97.0 & 0.000 & 28.456 \\
\hline$\{$ ADHD, MD, CUD $\} \rightarrow\{A \cup D\}$ & 32 & 5.2 & 51.6 & 0.000 & 3.287 \\
\hline$\{$ SUD $\} \rightarrow\{C U D\}$ & 31 & 5.1 & 86.1 & 0.000 & 5.415 \\
\hline$\{C D, A D\} \rightarrow\{C U D\}$ & 31 & 5.1 & 73.8 & 0.012 & 2.406 \\
\hline
\end{tabular}

Abbreviations: AD, anxiety disorder; ADHD, attention-deficit hyperactivity disorder; AUD, alcohol use disorder; CD, conduct disorder; CUD, cannabis use disorder; MD, mood disorder; MDD, major depressive disorder; NA, not applicable; ODD, oppositional defiant disorder; SUD, stimulant use disorder; TUD, tobacco use disorder.

Note: Only the rules with $p$-values less than 0.05 are shown in the table.

and other behavioral disorders. The Abram comorbidity study showed that among the participants diagnosed with SUD, ADHD, and other behavioral disorders account for $65.2 \%$, affective disorders (mood-related disorders) for
$25.7 \%$ and AD for $34.1 \%$. As compared with youth diagnosed with SUD, we obtained estimates of 258 cases (72.1\%) for conduct related disorders (according to DSM-5 classification) and another 176 (49.2\%) for neurodevelopment 
disorders like ADHD, which together stands at $70.8 \%$ of the total cases. Also, in our study, 193 (53.9\%) cases out of 358 SUD cases were diagnosed with DDs, and 80 (22.3\%) cases with AD. Our study's results provide a more comprehensive and updated view on the comorbid psychiatric disorders, both for DSM-5 broad categories and specific categories compared with any available literature on psychiatric comorbidity for youth detainees.

Using the ARM approach for data analysis provides insight into the conditional effects of comorbid psychiatric disorders. The association rules from ARM may answer the questions "if a patient has diagnoses of A, how likely it is for the patient to be diagnosed with $B$ as well? Is there any change in the likeliness of the patient being diagnosed with $B$ if the patient has diagnoses of both $A$ and C?" The ARM results showed that the odds for youth to be diagnosed with SUD range from 1.6 to 2.3 for youth patients diagnosed with $C D$, $A D, D D$, and their combinations. Also, the odds for youth to be diagnosed with $C D$ are higher with a stronger association for higher-order combinations of SUD, DD, and NDD. The ideal scenario for assessing of any of these disorders in a patient should include substantial consideration in delineating the symptoms and history before eliminating any of the potential comorbid conditions. Our results showed that the odds of CUD are very high with a strong association to co-occur with anxiety disorder, the odds of which increases when anxiety is combined with conduct disorder and when combined with AUD. Treating anxiety disorder with pharmacotherapy should receive careful consideration in choosing medications that are not likely to contribute to potentially adverse interactions with drugs and alcohol. ${ }^{41}$

Moreover, cognitive-behavioral therapy (CBT) has been highly effective against $\mathrm{AD}$; however, $\mathrm{CBT}$ alone is not sufficient for patients with anxiety and substance use disorders. $^{42,43}$ CBT can be beneficial if emphasized after controlling substance use because of the anxiety associated with the therapy may worsen substance use symptoms. ${ }^{44}$ DYS youth patients diagnosed with DDs like mood and major DDs combined with ADHD or CD showed higher odds of substance use disorders, like cannabis use. Cases like this where multiple disorders are present could be very challenging for providing treatment. Clinical data suggest that DDs can contribute to cannabis use, and there are very few studies to suggest a significant treatment effect of any pharmacotherapy on such comorbid patients. However, there is also a concern in selecting appropriate medications to reduce ADHD symptoms in the presence of substance abuse because of the risks of abusing ADHD medications.

Additionally, there is evidence that the association between ADHD and SUD becomes more robust in the presence of conduct disorder, ${ }^{45}$ which is also proven from our results. Integrated treatment therapies like integrated co-occurring treatment model, functional family therapy, family integrative transition, and multisystemic therapy have shown to be effective for juveniles with behavioral-related disorders (CD), substance-related disorders (SUD) in reducing recidivism, and delinquency. ${ }^{8}$ However, more research is needed to substantiate the effectiveness of integrated treatment plans for youth juveniles diagnosed with multiple comorbid conditions.

Moreover, there is evidence that the co-presence of multiple psychiatric disorders among the youth detainees can result in excessive psychotropic medications in their treatment. Such concomitant drug usages are associated with increased vulnerability to adverse drug interactions, risk of excessive dosing, risk of having premetabolic syndrome, and early death. ${ }^{46-48}$ Thus, we can suggest that the comorbid relations identified from our study can be utilized in designing a specific treatment regimen for youth with common diagnostic profiles.

However, one limitation of this data mining technique is that the ARM outcomes do not provide any causalities or directional effects regarding the psychiatric disorders. Thus, exactly what disorder was responsible for the onset of another disorder cannot be obtained from such analysis. Despite this, the findings of this study have usefulness in determining the best treatment strategies for these youth.

\section{Conclusion}

This study has found comorbidity to be prevalent among the youth patients of the MO DYS facilities receiving psychiatric services through the MUPC telemedicine network. Psychiatric disorders related to substance use, conduct, mood, anxiety, and ADHD have been found to overlap and have some conditional likelihood of co-occurring with one another.

\section{Clinical Relevance Statement}

The combination of psychiatric disorders can increase the complexity of treatment interventions, more likely to be intractable to traditional treatment, and subsequently cause treatment failures. Moreover, treating multiple psychiatric disorders simultaneously can be challenging as pharmacotherapy can effectively reduce symptoms from some disorders while worsening the effect on others. ${ }^{45,49}$ This implies that knowing of the conditional prevalence of disorders and the interplay of symptoms can help the psychiatrists determine the best treatment for the youth detainees with multiple disorders.

\section{Protection of Human and Animal Subjects}

The study was approved by University of XXX Institutional Review Board.

\section{Funding}

None.

Conflict of Interest

None declared.

\section{Acknowledgment}

The Missouri Division of Youth Services has collaborated with the University of Missouri, Department of Psychiatry in implementation of this program. 


\section{References}

1 Harp C, Hockenberry S, Sladky A. Juvenile Residential Facility Census, 2016: Selected Findings, National Report Series Bulletin. 2018. Available at: http://ncjj.org/Publication/Juvenile-Residential-Facility-Census-2016-Selected-Findings.aspx. Accessed January 16, 2020

2 Fazel S, Doll H, Långström N. Mental disorders among adolescents in juvenile detention and correctional facilities: a systematic review and metaregression analysis of 25 surveys. J Am Acad Child Adolesc Psychiatry 2008;47(09):1010-1019

3 Snyder HN. Juvenile Arrests, Office of Juvenile Justice and Delinquency Prevention, U.S. Department of Justice. 2002. Available at: https://www.ncjrs.gov/pdffiles1/ojjdp/223612.pdf. Accessed October 18, 2019

4 Skowyra K, Cocozza JJ. A blueprint for change: improving the system response to youth with mental health needs involved with the juvenile justice system. 2006. Available at: https://www. ncmhjj.com/wp-content/uploads/2013/07/2007_Blueprint-forChange-Full-Report.pdf. Accessed October 18, 2019

5 Burke JD, Mulvey EP, Schubert CA. Prevalence of mental health problems and service use among first-time juvenile offenders. J Child Fam Stud 2015;24(12):3774-3781

6 Grisso T. Adolescent offenders with mental disorders. Future Child 2008;18(02):143-164

7 Washburn JJ, Teplin LA, Voss LS, Simon CD, Abram KM, McClelland GM. Psychiatric disorders among detained youths: a comparison of youths processed in juvenile court and adult criminal court. Psychiatr Serv 2008;59(09):965-973

8 Underwood LA, Washington A. Mental illness and juvenile offenders. Int J Environ Res Public Health 2016;13(02):228

9 Gilbert AL, Grande TL, Hallman J, Underwood LA. Screening incarcerated juveniles using the MAYSI-2. J Correct Health Care 2015;21(01):35-44

10 Abram KM, Teplin LA. Co-occurring disorders among mentally ill jail detainees. Implications for public policy. Am Psychol 1991;46 (10):1036-1045

11 Abram KM, Teplin LA, McClelland GM. Comorbidity of severe psychiatric disorders and substance use disorders among women in jail. Am J Psychiatry 2003;160(05):1007-1010

12 Teplin LA, Abram KM, McClelland GM, Dulcan MK, Mericle AA. Psychiatric disorders in youth in juvenile detention. Arch Gen Psychiatry 2002;59(12):1133-1143

13 Barkley R. Attention-Deficit/Hyperactivity Disorder. New York City, NY: Guilford Publications; 2006

14 Frick PJ. Conduct Disorders and Severe Antisocial Behavior. Berlin, Germany: Springer Science \& Business Media; 1998

15 Costello EJ, Angold A, Burns BJ, et al. The great smoky mountains study of youth. Goals, design, methods, and the prevalence of DSM-III-R disorders. Arch Gen Psychiatry 1996;53(12): 1129-1136

16 Lewinsohn PM, Rohde P, Seeley JR. Major depressive disorder in older adolescents: prevalence, risk factors, and clinical implications. Clin Psychol Rev 1998;18(07):765-794

17 Abram KM, Teplin LA, McClelland GM, Dulcan MK. Comorbid psychiatric disorders in youth in juvenile detention. Arch Gen Psychiatry 2003;60(11):1097-110

18 Sobanski E. Psychiatric comorbidity in adults with attentiondeficit/hyperactivity disorder (ADHD). Eur Arch Psychiatry Clin Neurosci 2006;256(01, Suppl 1):i26-i31

19 Colins O, Vermeiren R, Vreugdenhil C, van den Brink W, Doreleijers T, Broekaert E. Psychiatric disorders in detained male adolescents: a systematic literature review. Can J Psychiatry 2010;55(04):255-263

20 Teplin LA, Abram KM, Washburn JJ, Welty LJ, Hershfield JA, Dulcan MK. The Northwestern juvenile project: overview. Available at: https://ojjdp.ojp.gov/sites/g/files/xyckuh176/files/pubs/234522. pdf. Accessed February, 2013
21 Chen T-J, Chou L-F, Hwang S-J. Application of a data-mining technique to analyze coprescription patterns for antacids in Taiwan. Clin Ther 2003;25(09):2453-2463

22 Tai Y-M, Chiu H-W. Comorbidity study of ADHD: applying association rule mining (ARM) to National Health Insurance Database of Taiwan. Int J Med Inform 2009;78(12):e75-e83

23 Held F, Le Couteur DG, Blyth FM, et al. Polypharmacy in older adults: association rule and frequent-set analysis to evaluate concomitant medication use. Pharmacol Res 2017;116:39-44

24 Boytcheva S, Angelova G, Angelov Z, Tcharaktchiev D. Mining comorbidity patterns using retrospective analysis of big collection of outpatient records. Health Inf Sci Syst 2017;5(01):3

25 Kost R, Littenberg B, Chen ES. Exploring generalized association rule mining for disease co-occurrences. AMIA. Annu Symp proceedings AMIA Symp. 2012;2012(2012):1284-1293. Available at: http:// www.ncbi.nlm.nih.gov/pubmed/23304407. Accessed November 13, 2019

26 Shen C-C, Hu L-Y, Hu Y-H. Comorbidity study of borderline personality disorder: applying association rule mining to the Taiwan national health insurance research database. BMC Med Inform Decis Mak 2017;17(01):8

27 Kim L, Myoung S. Comorbidity study of attention-deficit hyperactivity disorder (ADHD) in children: applying association rule mining (ARM) to Korean National Health Insurance Data. Iran J Public Health 2018;47(04):481-488

28 Wang C-H, Lee T-Y, Hui K-C, Chung M-H. Mental disorders and medical comorbidities: Association rule mining approach. Perspect Psychiatr Care 2019;55(03):517-526

29 American Psychological Association (APA). Diagnostic and statistical manual of mental disorders. American Psychiatric Publishing, Inc; 2013. Doi: 10.1176/appi.books.9780890425596.dsm04

30 Agrawal R, Imieliński T, Swami A. Mining association rules between sets of items in large databases. SIGMOD Rec 1993;22 (02):207-216

31 R Core Team. R: a language and environment for statistical computing. Available at: https://www.r-project.org/. Accessed 2018

32 Hahsler M, Chelluboina S, Buchta C. The arules R-package Ecosystem: analyzing interesting patterns from large transaction datasets. J Mach Learn Res 2011;12:1977:1981. Available at: http:// www.jmlr.org/papers/volume12/hahsler11a/hahsler11a.pdf

33 Borgelt C, Kruse R. Induction of Association Rules: Apriori Implementation. Hiedelberg: Compstat, Physica; 2002:395-400. Available at: https://link.springer.com/chapter/10.1007/978-3-64257489-4_59. Accessed June 26, 2019

34 Hahsler M. A probabilistic comparison of commonly used interest measures for association rules. Available at: https://michael. hahsler.net/research/association_rules/measures.html. Accessed May 28, 2020

35 Shaffer D, Fisher P, Dulcan MK, et al. The NIMH Diagnostic Interview Schedule for Children Version 2.3 (DISC-2.3): description, acceptability, prevalence rates, and performance in the MECA Study. Methods for the Epidemiology of Child and Adolescent Mental Disorders Study. J Am Acad Child Adolesc Psychiatry 1996;35(07):865-877

36 Bukstein OG, Horner MS. Management of the adolescent with substance use disorders and comorbid psychopathology. Child Adolesc Psychiatr Clin N Am 2010;19(03):609-623

37 van Emmerik-van Oortmerssen K, van de Glind G, van den Brink $\mathrm{W}$, et al. Prevalence of attention-deficit hyperactivity disorder in substance use disorder patients: a meta-analysis and metaregression analysis. Drug Alcohol Depend 2012;122(1-2):11-19

38 Rogers KM, Zima B, Powell E, Pumariega AJ. Who is referred to mental health services in the juvenile justice system? J Child Fam Stud 2001;10(04):485-494

39 Shelton D. Patterns of treatment services and costs for young offenders with mental disorders. J Child Adolesc Psychiatr Nurs 2005;18(03):103-112 
40 Hockenberry S, Wachter A, Sladky A. Juvenile residential facility census, 2014: Selected Findings. Available at: https://ojjdp. ojp.gov/sites/g/files/xyckuh176/files/pubs/250123.pdf. Accessed 2014

41 Brady KT, Verduin ML. Pharmacotherapy of comorbid mood, anxiety, and substance use disorders. Subst Use Misuse 2005; 40(13-14):2021-2041

42 Hesse M. Integrated psychological treatment for substance use and co-morbid anxiety or depression vs. treatment for substance use alone. A systematic review of the published literature. BMC Psychiatry 2009;9(01):6

43 Hofmann SG, Smits JAJ. Cognitive-behavioral therapy for adult anxiety disorders: a meta-analysis of randomized placebo-controlled trials. J Clin Psychiatry 2008;69(04):621-632

44 Kelly TM, Daley DC, Douaihy AB. Treatment of substance abusing patients with comorbid psychiatric disorders. Addict Behav 2012; 37(01):11-24
45 Upadhyaya HP. Substance use disorders in children and adolescents with attention-deficit/hyperactivity disorder: implications for treatment and the role of the primary care physician. Prim Care Companion J Clin Psychiatry 2008;10(03):211-221

46 Kukreja S, Kalra G, Shah N, Shrivastava A. Polypharmacy in psychiatry: a review. Mens Sana Monogr 2013;11(01):82-99

47 Ito H, Koyama A, Higuchi T. Polypharmacy and excessive dosing: psychiatrists' perceptions of antipsychotic drug prescription. Br J Psychiatry 2005;187(03):243-247

48 Misawa F, Shimizu K, Fujii Y, et al. Is antipsychotic polypharmacy associated with metabolic syndrome even after adjustment for lifestyle effects? a cross-sectional study. BMC Psychiatry 2011; $11: 118$

49 Hulvershorn LA, Quinn PD, Scott EL. Treatment of adolescent substance use disorders and co-occurring internalizing disorders: a critical review and proposed model. Curr Drug Abuse Rev 2015; $8(01): 41-49$ 